\title{
Validation of an analytical method by high-performance liquid chromatography and microbiological assay, biological safety and in silico toxicity for danofloxacin
}

\author{
Everson Willian Fialho Cordeiro ${ }^{1,2,5}{ }^{*}$, Renata Medeiros Hilgert ${ }^{1}$, Luiz Alcides das Chagas Batista ${ }^{1}$, \\ Raul Oliveira Souza ${ }^{3}$, Luís Flávio Souza de Oliveira ${ }^{3,4}$, Michel Mansur Machado ${ }^{\circledR 3,4}$, \\ Marcelo Donadel Malesuik ${ }^{1,4}$, Fávero Reisdorfer Paula ${ }^{1,4}$, Cheila Denise Ottonelli Stopigliaa, \\ Clésio Soldateli Paim ${ }^{1,4}$
}

${ }^{1}$ Laboratório de Pesquisa em Desenvolvimento e Controle de Qualidade, Universidade Federal do Pampa, Uruguaiana (RS), Brasil, ${ }^{2}$ Laboratório de Microbiologia, Universidade Federal do Pampa, Uruguaiana (RS), Brasil, ${ }^{3}$ Núcleo de Pesquisa em Bioquímica, Toxicologia e Imunologia, Universidade Federal do Pampa, Uruguaiana (RS), Brasil, ${ }^{4}$ Programa de PósGraduação em Ciências Farmacêuticas, Universidade Federal do Pampa, Uruguaiana (RS), Brasil, ${ }^{5}$ Programa de PósGraduação em Farmácia, Área Fisiopatologia e Toxicologia, Faculdade de Ciências Farmacêuticas, Universidade de São Paulo, São Paulo (SP), Brasil

\begin{abstract}
Danofloxacin is a veterinary fluoroquinolone used to treat respiratory and gastrointestinal diseases of birds, pigs and cattle. The literature reviewed shows some analytical methods to quantify this fluoroquinolone, but microbiological and biological safety studies are limited. The analytical methods were validated by the Official Codes. The LC-DAD method was developed and validated using an RP-18 column, mobile phase containing a mixture of $0.3 \%$ triethylamine $(\mathrm{pH} 3.0)$ and acetonitrile $(85: 15, v / v)$. The microbiological assay was performed by agar diffusion method $(3 \times 3)$ and Staphylococcus epidermidis as a microorganism test. Forced degradation studies were performed in both methods. The minimum inhibitory concentration (MIC) was performed by test microdilution and toxicity studies were evaluated using in silico study, cell proliferation, cell viability test, micronuclei and comet assay. LC and a microbiological assay proved linear, accurate, precise, and robust to quantify danofloxacin, but only the LC method showed selectivity to quantify the drug in the presence of its degradation products. These results demonstrate that the LC method is suitable for stability studies of danofloxacin, but a microbiological assay cannot be used to quantify the drug due to the biological activity of the photoproducts. Ex-vivo cytotoxicity and theoretical and experimental genotoxicity were also observed.
\end{abstract}

Keywords: Danofloxacin. Microbiological assay. Biological safety. In silico toxicology. Fluoroquinolones photodegradation.

\section{INTRODUCTION}

Danofloxacin (DAN) (1-cyclopropyl-6-fluoro-7[(1S,4S)-5-methyl-2,5-diazabicyclo[2.2.1]heptan-2-yl]4-oxoquinoline-3-carboxylic acid) is a fluoroquinolone synthetic analogue of ciprofloxacin and was introduced in the world market in 1991 for the treatment of diseases related to the respiratory and gastrointestinal tracts of birds, pigs and cattle (Mckellar, Gibson, McCormac, 1998; Kaur et al., 2012).

\footnotetext{
*Correspondence: E. Fialho. Laboratório de Pesquisa em Desenvolvimento e Controle de Qualidade, Universidade Federal do Pampa, Uruguaiana, RS, Brasil. E-mail: e_willianfc@hotmail.com
}

The drug has a broad spectrum of action against Gram negative and Gram positive bacteria, as well as mycoplasma and against intracellular pathogens such as Chlamydia and Brucella (Mckellar, Gibson, McCormac, 1998; Escudero et al., 2007; Soler, 2014).

The development of fluoroquinolones led to major advances in the treatment of infections due to their high potency, broad spectrum, bactericidal activity, in addition to optimal pharmacokinetic characteristics and their use both in medicine and in veterinary medicine (Soler, 2014; Souza et al., 2004; Picó, Andreu, 2007; Wolfson, Hooper, 1985).

The International Conference on Harmonisation 
$(\mathrm{ICH})$ and the International Cooperation on Harmonisation of Technical Requirements for Registration of Veterinary Medicinal Products (VICH), describe and recommend drugs for stability studies with a view to developing methods for the quantification, identification and structure elucidation of drugs and their respective degradation products. Currently, this is one of the minimum requirements for the registration of drugs and drug products. Moreover, biological safety studies are necessary in order to ensure the effectiveness and safety of such products (ICH, 2003; VICH, 1998).

The literature review shows some physicochemical methods to quantify this fluoroquinolone. Hubicka et al. (2014) describes a method of quantification by LC to DAN in the presence of photoproducts. Liu et al. (2011) published a study using LC-MS for the quantification of hydrolysis products, oxidation and photolysis. A study by LC-MS to determine the drug in bovine muscle and milk is also described (Van Hoof et al., 2005). Galarini et al. (2009) report the separation of quinolones introduced in animal feed using LC with fluorescence and ultraviolet detection. Rodríguez-Cáceres et al. (2009) developed an LC method using electrochemical detection and a cell with high sensitivity for the simultaneous determination of DAN, difloxacin and sarafloxacin. However, microbiological studies are limited and there are no cytotoxicity and genotoxicity studies for DAN in the presence of its degradation products.

In this sense, these studies aimed to develop and validate a stability indicating method by LC and microbiological assay for the quantitative determination of DAN mesylate in injectable solution, to determine the MIC and assess drug genotoxicity and cytotoxicity in the presence of its degradation products obtained under stressed conditions. The potential toxicity of degradation products was also evaluated by different software in order to verify if the drug could damage biological cells. These results may help to understand the mechanisms of toxic effects which could be caused by the compounds generated by DAN.

\section{MATERIAL AND METHODS}

\section{Chemicals}

The chemical reference substance of DAN (DAN CRS) was acquired from Sigma-Aldrich ${ }^{\circledR}$ (St. Louis, MO, USA). The injectable solution $\left(\right.$ Advocin $^{\circledR} 2.5 \%$, Pfizer ${ }^{\circledR}$ ) was acquired from Agroline ${ }^{\circledR}$ Agricultural Products (Campo Grande/MS, Brazil). Chemicals used were of analytical grade or LC grade. Purified water was prepared using Milli-Q Plus ${ }^{\circledR}$ (Millipore, Bedford, USA). The formulation excipients were all pharmaceutical grade and were purchased from different suppliers: 2-pyrrolidone (Merck $\left.{ }^{\circledR}\right)$, povidone CI5 (Sigma -Aldrich ${ }^{\circledR}$ ), magnesium oxide (Synth $\left.{ }^{\circledR}\right)$, phenol (Merck $\left.{ }^{\circledR}\right)$, monothioglycerol (Sigma -Aldrich $\left.{ }^{\circledR}\right), \mathrm{HCl}$ (Nuclear ${ }^{\circledR}$ ), $\mathrm{NaOH}$ (Nuclear ${ }^{\circledR}$ ) and purified water (Milli-Q Plus ${ }^{\circledR}$ ). The Mueller Hinton culture media was acquired from Himedia ${ }^{\circledR}$ (Mumbai, India) and the antibiotic number 11 was acquired from Merck $^{\circledR}$ (Darmstadt, Germany).

\section{Apparatus}

A Shimadzu Prominence ${ }^{\circledR}$ liquid chromatograph (Kyoto, Japan) equipped with a model LC-20AD quaternary pump, SIL-20AC HT auto sampler, CTO20AC column oven, SPD-M20A photodiode-array detector and LC Solution V. 1.24 SP1 manager system software was used. Photodegradation studies were carried out in a photostability UV chamber $(1.0 \times 0.17 \times 0.17 \mathrm{~m})$ with mirrors and equipped with Ultraviolet-C radiation lamps (UVC, Light Express ${ }^{\circledR}, 254.0 \mathrm{~nm}$ ). An electronic caliper (Mitutoyo ${ }^{\circledR}$, Tokyo, Japan) was utilized to measure the diameters in the zone of growth inhibition ( $\mathrm{mm}$ ). A spectrophotometer (Analyser ${ }^{\circledR}$, São Paulo, Brazil) was used in the microorganism standardization. A Nova Ética dry heat incubator (São Paulo, Brazil) was used in the thermal degradation studies.

\section{Chromatographic conditions by LC method}

The chromatographic separation was performed in a Supelco Ascentis ${ }^{\circledR}$ column RP-18 (150 x 4.6 mm I.D., $5 \mu \mathrm{m}$, St. Louis, MO, United States). The mobile phase comprised a mixture of $0.3 \%$ triethylamine ( $\mathrm{pH}$ adjusted to 3.0 with $10 \%$ formic acid, $v / v)$ and acetonitrile $(85: 15, v / v)$ at a flow-rate of $1.0 \mathrm{~mL} \mathrm{~min}^{-1}$ with isocratic elution. The injection volume was $20 \mu \mathrm{L}$ for both reference substance and drug product solutions and the run time was $8 \mathrm{~min}$. The temperature was set at $30^{\circ} \mathrm{C}$ in the column oven. The drug was determined by UV detection at $283.0 \mathrm{~nm}$ using a diode array detector (DAD).

\section{Agar diffusion bioassay ( $3 \times 3)$}

The bioassay followed the $3 \times 3$ parallel line assay design with three doses of the standard and three doses of the sample in each plate, using eight plates for each assay, according to the procedure described in USP 38 (2015). The base layer agar was composed by $20 \mathrm{~mL}$ of medium number 11 that was poured into $100 \mathrm{~mm} \times 20 \mathrm{~mm}$ 
Petri dishes. After that layer solidified, $5.0 \mathrm{~mL}$ portions of the antibiotic medium number 1 were poured onto the base layer. In each plate, six stainless steel cylinders of the same size $(8 \mathrm{~mm} \times 6 \mathrm{~mm} \times 10 \mathrm{~mm})$ were placed on the surface of the inoculated medium. Three alternate cylinders were filled with $200 \mu \mathrm{L}$ of the reference solutions (S1, S2, and S3), and the other three cylinders were filled with the sample solutions (T1, T2, and T3). The plates were incubated at $35 \pm 2{ }^{\circ} \mathrm{C}$ for $18 \mathrm{~h}$. The diameters of the growth inhibition were carefully measured with an electronic caliper.

The preliminary tests were performed using Staphylococcus aureus ATCC 6531p, Staphylococcus epidermidis ATCC 12228 and Escherichia coli ATCC 10536 as microorganism tests. The $24 \mathrm{~h}$ growth of the microorganisms at $35 \pm 2{ }^{\circ} \mathrm{C}$ was suspended in $0.9 \% \mathrm{NaCl}$ sterile solution and standardized in a spectrophotometer ( $25 \pm 2 \%$ transmittance, $580 \mathrm{~nm})$. A $2 \%$ inoculum solution was prepared from this solution in number 11 medium.

The potency of the drug was statistically calculated by parallel line model, designed for the $3 \times 3$ testing assay. An analysis of variance (ANOVA) was used for the statistical validation of tests, evaluating the regression parallelism and linearity of each test (USP 38, 2015; Hewitt, 2003; Brazilian Pharmacopeia, 2010).

\section{Validation of the analytical method by LC and microbiological assay}

The analytical methods were validated according to the Guide for Validation and Analytical Quality Control (GVCQA) (Brasil, 2011) and other Official Codes (USP 38, 2015; Hewitt, 2003; Brazilian Pharmacopeia, 2010). The parameters available were specificity, linearity, precision, accuracy and robustness. The limits of detection (LOD) and quantification (LOQ) were determined only for the LC method.

\section{Preparation of DAN CRS and Sample solutions for the LC method}

An accurately weighed amount of DAN CRS $(5.0 \mathrm{mg})$ was transferred to a $100 \mathrm{~mL}$ volumetric flask and dissolved in purified water to obtain a final concentration of $50.0 \mu \mathrm{g} \mathrm{mL} \mathrm{m}^{-1}$. Successive dilutions were performed in the same diluent to obtain a concentration of $10.0 \mu \mathrm{g} \mathrm{mL}^{-1}$ in DAN.

To prepare a sample solution, an aliquot of $1 \mathrm{~mL}$ of the injectable solution (Advocin ${ }^{\circledR} 2.5 \%$ ) was transferred to a $100 \mathrm{~mL}$ volumetric flask, completed to volume with purified water and homogenized, obtaining a solution of $250 \mu \mathrm{g} \mathrm{mL}^{-1}$ in DAN. Successive dilutions were performed in the same diluent to obtain a concentration of $10.0 \mu \mathrm{g} \mathrm{mL}^{-1}$ in DAN.

All the solutions were protected from light and filtered through a $0.45 \mu \mathrm{m}$ membrane filter before injection.

\section{Preparation of DAN CRS and Sample solutions for the microbiological assay}

DAN CRS was dissolved in purified water to obtain a solution of $250.0 \mu \mathrm{g} \mathrm{mL}^{-1}$. Aliquots of DAN CRS and Advocin ${ }^{\circledR}$ were diluted in $\mathrm{pH} 5.8$ phosphate buffer, to achieve concentrations of 5.0,10.0, and $20.0 \mu \mathrm{g} \mathrm{mL}^{-1}$ (S1, S2, and S3, respectively for DAN CRS and T1, T2, and T3, respectively for Advocin ${ }^{\circledR}$ ). All solutions were protected from light.

\section{Specificity}

Forced degradation studies were performed to provide the stability-indicating property and specificity of proposed methods. The interference of excipients in both methods was evaluated and blank solutions were used during the analysis. For the peak purity test for the LC method, a DAD was used and the purity factor was also evaluated as a support to analyze peak homogeneity. The stress conditions were then performed under photolytic, acid, basic, oxidative and thermal conditions for the LC method and only under photolytic conditions during 48 hours for the microbiological assay.

\section{Photolytic conditions}

Aliquots of sample solution $\left(250 \mu \mathrm{g} \mathrm{mL} \mathrm{m}^{-1}\right.$ in DAN) were transferred to a quartz cuvette, irradiated for 1,2, 4, $8,12,24$, and 48 hours in a photodegradation chamber. After the time of exposure, dilutions were performed in purified water to obtain a final concentration of 10.0 $\mu \mathrm{g} \mathrm{mL}^{-1}$ in DAN. Control samples were prepared using the same procedure described below and also placed exposed concurrently into the light chamber, protect with aluminium foil, to verify the interference of the temperature in the experiments."

\section{Thermal conditions}

Aliquots of sample solution $\left(250 \mu \mathrm{g} \mathrm{mL}^{-1}\right.$ in DAN) were transferred to eppendorfs and put in a dry heat incubator at a controlled temperature of $80 \pm 2{ }^{\circ} \mathrm{C}$ for different time intervals $(1,2,4,6,8$ and 24 hours). After the 
time of exposure, dilutions were performed in purified water to obtain a final concentration of $10.0 \mu \mathrm{g} \mathrm{mL} \mathrm{L}^{-1}$ in DAN.

\section{Acid and alkaline conditions}

To evaluate DAN stability in acid and alkaline conditions, aliquots of the injectable solution were diluted in $\mathrm{NaOH}$ and $\mathrm{HCl}$ solutions $\left(1,2\right.$, and $\left.5 \mathrm{~mol} \mathrm{~L}^{-1}\right)$ to obtain a concentration of $250 \mu \mathrm{g} \mathrm{mL}^{-1}$ in DAN. These solutions were maintained for 1, 2, 4, 6, 8, and 24 hours, neutralized and diluted with purified water to obtain a final concentration of $10.0 \mu \mathrm{g} \mathrm{mL}^{-1}$ in DAN.

\section{Oxidative conditions}

To evaluate the behaviour of the drug under oxidative conditions, aliquots of the injectable solution were diluted with $3 \%$ or $30 \%$ hydrogen peroxide solution. The drug was maintained under these conditions for 1,2 , $4,6,12$, and 24 hours and diluted with purified water to obtain a final concentration of $10.0 \mu \mathrm{g} \mathrm{mL}^{-1}$ in DAN.

\section{Excipients}

An amount of formulation excipients contained in $2.5 \%$ injectable solution of danofloxacin was dissolved in purified water, transferred to a $25.0 \mathrm{ml}$ volumetric flask and the volume was completed using the same diluent. The same aliquots used to prepare the sample solutions were withdrawn and the volume diluted with purified water.

\section{Linearity}

The linearity of the LC method was performed using three calibration curves with six concentrations $(2.5$; $5.0 ; 7.5 ; 10.0 ; 15.0$; and $20.0 \mu \mathrm{g} \mathrm{mL}^{-1}$ ) of DAN CRS in purified water. For each concentration the solutions were prepared and injected in triplicate. The regression line was calculated using the method of least squares and the curves were validated through analysis of variance.

The linearity of the microbiological assay was carried out using three levels of CRS DAN concentrations (5.0; 10.0; and $20.0 \mu \mathrm{g} \mathrm{mL}^{-1}$ ) in phosphate buffer $\mathrm{pH} 5.8$. Standard curves were obtained on different days and measures of inhibition zones were plotted on graphs of inhibition zones versus logarithm of the concentration.

\section{Precision}

The precision in both methods was evaluated using the parameters of repeatability and intermediate precision, performed on different days by different analysts. The results were expressed as RSD of the analytical measurements.

\section{Accuracy}

The accuracy of the methods was calculated as recovery percentage by adding known amounts of the DAN CRS solutions to sample solutions.

\section{Robustness}

A Plackett-Burman experimental design of 12 experimental runs was performed to verify the robustness of the LC method. The factors investigated were: $\mathrm{pH}$ of aqueous phase $(3.0 \pm 0.2)$, percentage of acetonitrile

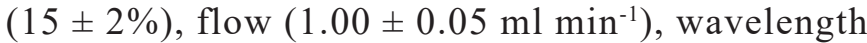
of detection $(283 \pm 3 \mathrm{~nm})$ and column manufacturer $\left(\right.$ Supelco $^{\circledR}$ and Shimadzu $^{\circledR}$ ). To evaluate the robustness of the microbiological assay, the factors assessed were the inoculum concentrations (1.7\% and $2.3 \%)$ and the use of different ovens for incubation of the plates.

\section{LOD and LOQ}

LOD and LOQ of the drug using the LC method were obtained based on the signal-to-noise approach described by Ermer and Miller (2005). The background noise was obtained after injection of the blank solution, observed over a distance equal to 20 times the width at half-height of the DAN peak $\left(10.0 \mu \mathrm{g} \mathrm{mL}^{-1}\right)$. LOD and LOQ values were experimentally determined with six replicates using the signal-to-noise ratio of $3: 1$ and 10:1, respectively.

\section{Minimum inhibitory concentration (MIC)}

\section{Microorganism standardization}

The assays to determine the MIC were performed according to protocol M100-S25 of the Clinical and Laboratory Standards Institute (CLSI, 2015). The microbial suspension was standardized using optical density at $530.0 \mathrm{~nm}$ in the range of 0.09 to $0.13 \mathrm{~A}$. Assays were performed using these solutions diluted in Mueller Hinton broth at a ratio of 1:10 $(v / v)$.

\section{Microdilution assay}

In order to prepare a sample solution, aliquots of injectable solution (Advocin ${ }^{\circledR}$ 2.5\%) were diluted using purified water obtaining a concentration of $10 \mu \mathrm{g} \mathrm{mL}^{-1}$ in 
DAN. Shortly after, successive solutions were performed in Mueller Hinton culture medium to obtain final concentrations ranging from 0.03 to $12.8 \mu \mathrm{g} \mathrm{mL}^{-1}$.

The tests were performed in sterile plates containing 96 wells in which aliquots of $100.0 \mu \mathrm{L}$ of various concentrations of the antimicrobial agent were added. Subsequently, aliquots of $5.0 \mu \mathrm{L}$ of the standardized inoculum were added to each well. An antibioticfree control (growth control) and a free control of microorganisms (sterility control) were included in the tests and the plates were incubated at $35 \pm 2{ }^{\circ} \mathrm{C}$, for 18-24 h. The MIC determination was carried out by visual comparison to the growth control, and all assays were performed in triplicate.

After the MIC was defined, further tests were conducted to evaluate the drug activity which showed changes when it was exposed to stress conditions by UV-C radiation for 12, 24, and 48 hours, prepared as described in the LC method.

\section{Biological safety studies}

The white blood cell cultures were prepared using a blood sample collected from a volunteer donor, according to procedures approved by the Research Ethics Committee of the Federal University of Santa Maria (Letter of approval No. 27045614.0.0000.5323). Venous blood was immediately diluted in RPMI 1640 supplemented with $10 \%$ fetal bovine serum, $5 \%$ phytohemagglutinin, sodium bicarbonate $2 \mathrm{~g} \mathrm{~L}^{-1}$, and $1 \%$ streptomycin/ penicillin at the proportion of $1: 1(\mathrm{v} / \mathrm{v})$. The cells were placed in an incubator at $37^{\circ} \mathrm{C}$ and $5 \% \mathrm{CO}_{2}$, for 72 hours (Montagner et al., 2010). Four groups were used for the tests and the negative control received PBS 7.4 and the positive control $100 \mathrm{mM}$ hydrogen peroxide.

The concentrations tested ranged between 125 and $0.97 \mu \mathrm{g} \mathrm{mL}^{-1}$ of the drug in PBS 7.4 buffer. The drug was also submitted to forced degradation under photolytic conditions (48 hours) to evaluate the toxic potential in the presence of degradation products. All assays were performed in triplicate.

The study of cellular viability was evaluated by the loss of membrane integrity using the trypan blue test. Cells exposed to the dye were analyzed microscopically in a Neubauer chamber and the results were expressed as percentage of the control value (Burow et al., 1998).

Cell proliferation analyses were also performed in a Neubauer chamber to differentiate between living and dead cells, observing the blue colour of the dead cells using Turk's solution as a dye (3\% acetic acid and $1 \%$ gentian violet in water) (Tice et al., 2000).
The comet assay was performed according to Montagner et al. (2010) and Tice et al. (2000). One hundred cells per slide were counted in triplicate for each group. Cells were classified according to the length of their tail, and the levels of damage were from 0 (no damage) to 4 (maximum damage).

The micronucleus test was carried out according to the technique described by Schmid (1975), which allows the identification of increased frequency of micronuclei in cells exposed to genotoxic agents, which express damage in their chromosomes.

All analyses were performed using toxicity specific statistical software. Data were evaluated by ANOVA followed by post-hoc Bonferroni. Results were considered significant to $\mathrm{p}<0.05$.

\section{LC-ESI-MS instrumentation and conditions}

An LC-ESI-MS method was performed using a Shimadzu ${ }^{\circledR}$ instrument equipped with an MS detector. The separation was performed using a Supelco Ascentis ${ }^{\circledR}$ column $(150 \times 4.6 \mathrm{~mm}, 5 \mu \mathrm{m})$ at $30{ }^{\circ} \mathrm{C}$ with a mobile phase consisting of the mixture of $0.1 \%$ formic acid and acetonitrile $(85: 15, v / v)$ in isocratic gradient at a flow- rate of $0.5 \mathrm{~mL} \mathrm{~min}^{-1}$ with an injection sample volume of $2.0 \mu \mathrm{L}$.

Studies were performed in samples obtained after exposition to photolytic conditions using UVC radiation, for 24 hours. Mass spectra were acquired with an electrospray ionization interface in positive ionization mode. The capillary voltage was $2.5 \mathrm{kV}$; source temperature $110{ }^{\circ} \mathrm{C}$; desolvation temperature $250{ }^{\circ} \mathrm{C}$; nitrogen desolvation flow $900 \mathrm{~L} \mathrm{~h}^{-1}$; nitrogen cone flow $90 \mathrm{~L} \mathrm{~h}^{-1}$. The full scan mass spectrum was acquired over a range of $\mathrm{m} / \mathrm{z} 50-900$.

\section{In silico toxicology}

Chemical structures of degradation products identified by LC-ESI-MS and confirmed in the studies of Hubicka et al. (2014) were submitted to evaluation of a theoretical risk of causing toxic effects using three in silico toxicity programs, such as Osiris Property Explorer ${ }^{\circledR}$ (2017), ADME-Tox ACD/Labs (2017), and pKCSM free web software (2017). Osiris Property Explorer was used to determine the potential mutagenic, tumorigenic, irritant, and toxicant reproductive system effects.

ADME-Tox web server software, ACD/Labs team ${ }^{\circledR}$, was used to study the genotoxic and mutagenic effects, using data of a bacterial reverse mutation test (AMES Test) Salmonella typhimurium TA97a, TA98, TA100, TA102, TA104, TA1535, TA1537 and TA1538. Other software 
used to predict the toxicity of degradation products are PKCSM which is a free web software used to determine the potential toxic effects, such as hERG I and II inhibitor, hepatotoxicity, AMES toxicity, and skin sensitization (Pires, Blundell, Ascher, 2015).

\section{RESULTS AND DISCUSSION}

\section{Development and validation of the LC method}

The chromatographic conditions were chosen after testing different mobile phases with distinct ratios of organic solvent (acetonitrile or methanol) and water, with and without triethylamine at different $\mathrm{pH}$ values. Ammonium acetate buffers were also tested. The use of acetonitrile as an organic component and the addition of triethylamine $(0.3 \%, v / v)$ in the aqueous phase $(\mathrm{pH} 3.0)$ improved peak symmetry.

The mobile phase consisting of $0.3 \%$ triethylamine $\mathrm{pH} 3.0$ (adjusted with 10\% formic acid solution, $v / v)$ and acetonitrile $(85: 15, v / v)$ showed the best system suitability values, with suitable resolution between the drug and the degradation products and results in terms of peak parameters (peak shape, theoretical plates, symmetry and retention factor) according to the range recommended (USP 38, 2015). Moreover, the retention time observed $(\mathrm{rt}=6.0 \mathrm{~min})$ allows for a rapid determination of the drug.

Figure 1 showed that formulation excipients (1A) did not interfere in the quantification of the drug (1B - DAN CRS). Moreover, the method demonstrated selectivity to quantify the drug in the presence of degradation products, obtained from stress conditions.
The result showed that under oxidative conditions (Figure 1C) it was possible to verify the formation of two degradation products, detected at 3.63 and 6.75 minutes. Under these conditions the drug degraded $19.3 \%$ and $35.1 \%$ in 12 and 24 hours, respectively.

Under photodegradation conditions (Figure 1D), three degradation products were formed $(3.23,4.14$, and $11.47 \mathrm{~min}$.). The drug degraded $15.25 \%$ in 24 hours and $25.5 \%$ in 48 hours. These results showed the drug instability under photolytic and oxidative conditions. Control samples demonstrated that the heat generated inside the light chamber did not interfere in drug degradation.

The concentration of danofloxacin decreased significantly under oxidative and photolytic conditions. However, there were no changes in drug concentration when the drug was exposed to alkaline and acid hydrolysis (1.0; 2.0 and $5.0 \mathrm{~mol} \mathrm{~L}^{-1}$ ) and temperature of $80^{\circ} \mathrm{C}$ for $24 \mathrm{~h}$.

The chromatographic peak purity tool, applied to DAN peaks, demonstrated that they were pure in all cases, confirming the absence of another substance coeluting at the same retention time. Moreover the method proves to be a stability indication and there is a clear ability to assess the drug unequivocally in the presence of potential interference.

To assess linearity, three standard curves for DAN CRS were constructed by plotting concentration ( $\mu \mathrm{g}$ $\mathrm{mL}^{-1}$ ) versus area (mAU). The results showed adequate linearity in the range of 2.5 and $20.0 \mu \mathrm{g} \mathrm{mL}^{-1}$. The linear equation, obtained by linear regression by minimum squares method, was $y=180679 x-137386$ and the correlation coefficient $(r)$ was 0.9994 , indicating a linear

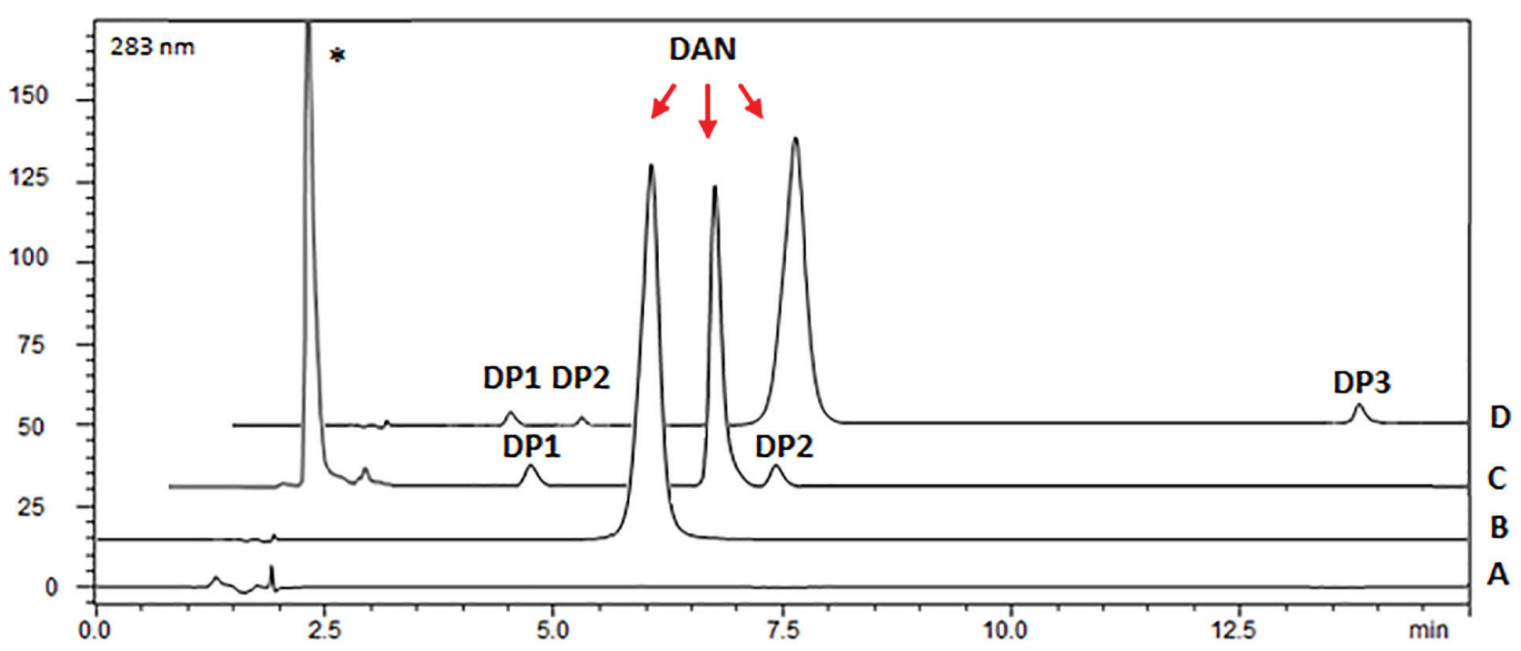

FIGURE 1 - Chromatograms obtained from DAN in injectable solution by LC: (A) placebo solution of excipients; (B) drug product DAN; (C) oxidative degradation $\left(30 \% \mathrm{H}_{2} \mathrm{O}_{2}\right.$, for 24 hours); (D) photodegradation (UV-C radiation, for 48 hours). * hydrogen peroxide preservative. 
relationship between the concentrations and the areas obtained. The ANOVA results showed linear regression, with no deviation from linearity $(\alpha=0.05)$, confirming the linearity of the analytical method.

The precision of the analytical method was demonstrated by repeatability (intraday) and intermediate precision (interday). The experimental values obtained for quantitative determination of the drug in three days were $101.23 \pm 0.88 \%, 100.95 \pm 1.4 \%$ and $104.33 \pm 1.8 \%$. The low variability of the results indicated method precision.

Results showed method accuracy using the standard addition technique. The average recovery percentages were in the range of $99.45 \pm 0.62 \%, 99.93 \pm 0.76 \%$ and $100.21 \pm 0.82 \%$, demonstrating the accuracy of the method.

The method can be considered robust because none of the studied factors showed a significant effect $(\alpha=$ 0.05 ) on the quantification of DAN (Table I). Besides, the variation of robustness results $(\mathrm{RSD}=0.79 \%)$ is in accordance with the results of the precision assay.

\section{Microbiological assay}

All microorganisms used in the microbiological assay showed sensitivity to the drug, but significant differences could be seen between the growth inhibition zones. The assay using Staphylococcus epidermidis at
5.0, 10.0 and $20.0 \mu \mathrm{g} \mathrm{mL}^{-1}$ showed well defined growth inhibition zones, allowing an accurate and precise determination.

Curves of DAN CRS, constructed by plotting log concentration versus growth inhibition zone, showed good linearity in the studied concentration range, with a mean correlation coefficient $(r=0.9998)$ and linear equation, obtained by linear regression by the minimum squares method, was $\mathrm{y}=7.136 \mathrm{x}+14.71$.

Assay precision was determined by repeatability (intraday) and intermediate precision (interday). Repeatability was assessed by determining the power of the samples in three tests performed simultaneously at the same concentrations and under the same experimental conditions. The results showed RSD values lower than $5.0 \%$, indicating the intra-assay precision. The antimicrobial activity comprises a range from $102.9 \%$ to $106.7 \%$ and RSD of $1.3 \%$.

The robustness of the analytical method was evaluated using different concentrations of inoculum ( \pm $0.3 \%$ ) and different air ovens. The modification in the inoculum concentration showed results in the range of $103.5 \%$ to $104.76 \%$ and the alteration of the air oven showed a result with a $103.18 \%$ potency. These values obtained are within the range found in the precision studies, confirming the robustness of the analytical method.

TABLE I - Plackett-Burmann experimental design to evaluate the robustness of the analytical method

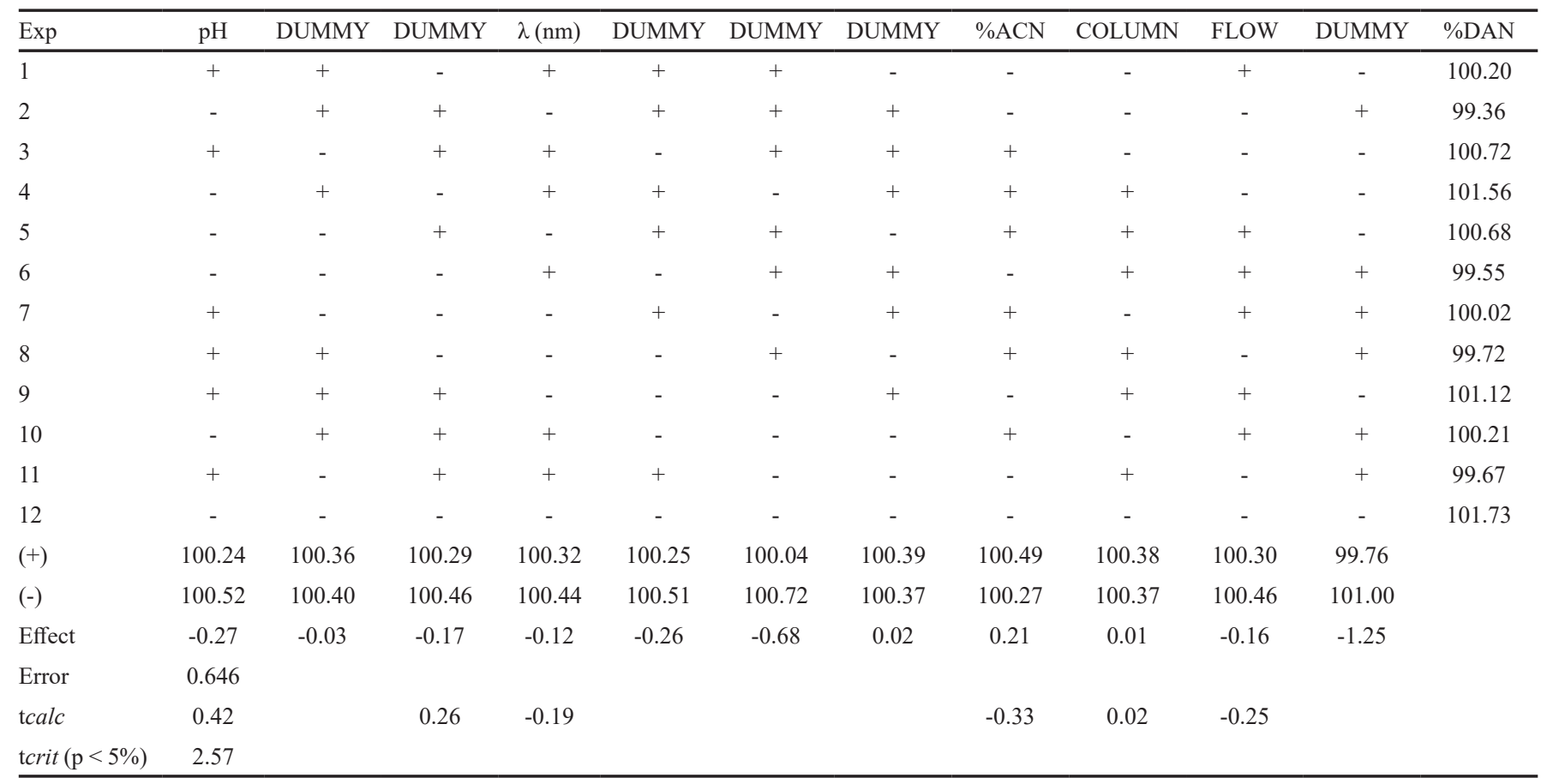

The LOD and LOQ for the proposed method were 0.13 and $0.52 \mu \mathrm{g} \mathrm{mL} \mathrm{m}^{-1}$, respectively, evidencing the sensitivity of the analytical method. 
The specificity of the microbiological assay was performed to verify the interference of formulation excipients and degradation photoproducts formed under stress conditions. The results showed that the placebo solution did not produce growth inhibition zones, demonstrating that it did not interfere. Furthermore, the diameters of the growth inhibition zones were not increased when excipients were added to the DAN CRS.

The same conditions employed in the forced degradation studies using the LC method were applied in microbiological assays. The results showed that the drug potency was not decreased using the degraded samples under photolytic conditions, suggesting that the photodegradation products have biological activity, which limits the drug quantification in stability studies using the microbiological assay. However, the LC method proved suitable to quantify the DAN drug and can be used as routine analysis and stability studies. The oxidative stress conditions could not be assessed due to the bactericidal activity of the $30 \% \mathrm{H}_{2} \mathrm{O}_{2}$ solution.

\section{Microdilution assay}

The in vitro susceptibility of the three strains examined is shown in Table II. The samples subjected to stress conditions showed that the residual of drug levels is reduced over time as discussed above. However, when comparing the assay in vitro samples submitted to photodegradation with the undegraded samples, some changes are identified in the MIC.

After 12 hours of degradation, the drug content is reduced to $93 \%$, and the MIC obtained for S. aureus remains the same. However, after 24 and 48 hours, the concentration required to inhibit growth was twice the MIC for the drug. The opposite was found for $S$. epidermidis, where danofloxacin in the presence of degradation products (DAN DP) at 24 and 48 hours, had higher activity when compared to DAN and DAN DP at 12 hours. Regarding the DAN MIC for $E$. coli, the result shows that drug activity is reduced with degradation. However, the reduction of the MIC is not directly proportional to the drug content.

\section{Biological safety testing}

The evaluation of toxicity using parameters and leukocyte cultures has proved to be a significant in vitro research tool for evaluating damage to membranes, cellular activity and proliferation index. The results of the effect of DAN and DAN DP at 48 hours in leukocyte proliferation are shown in Figure 2A and it is possible to observe a significant difference between the groups tested. The amount of cells declined significantly at higher concentrations of DAN DP (125.0 and $62.5 \mu \mathrm{g} \mathrm{mL}^{-1}$ ), as also described for positive control. However, no significant changes were observed in the number of leucocytes at other concentrations (31.25 to $\left.0.97 \mu \mathrm{g} \mathrm{mL}^{-1}\right)$ in the same group and these results were statistically similar to the negative control $(\mathrm{p}=0.05)$.

The percentage of viable cells (Figure 2B) exposed to DAN drug was not significantly decreased compared with the negative control, demonstrating that the drug proved non-toxic at the concentrations applied. However, DAN DP showed similar behaviour to the positive control group, indicating that the degradation products may be responsible for damage to the membrane by promoting cell death. Similar results were obtained for the gemifloxacin degradation product, where significant dose-dependent cytotoxic and genotoxic activity was verified using rat fibroblast (3T3) (Paim et al, 2013).

The DNA Damage Index (DDI) (Figure 2C) was evaluated by comet assay. The trials indicated that none of the concentrations of DAN drug (range of 125.0 to $0.97 \mu \mathrm{g} \mathrm{mL}^{-1}$ ) and DAN DP at 31.25 to $0.97 \mu \mathrm{g} \mathrm{mL}^{-1}$ demonstrated genotoxic potential, because the results were statistically similar to negative control $(p=0.05)$. However, DAN PD showed a genotoxic potential at high concentrations (125.0 and $62.5 \mu \mathrm{g} \mathrm{mL}^{-1}$ ), because the damage index results were statistically different from the negative control.

The results of micronuclei formation in the cell cultures can be observed in Figure 2D. The trials indicated that high concentrations of DAN drug and DAN DP (125.0 and $62.5 \mu \mathrm{g} \mathrm{mL}^{-1}$ ) may be responsible for the formation of micronuclei in the cells used in these studies.

TABLE II - Minimal inhibitory concentration (MIC) to danofloxacin in absence or in the presence of degradation products (DAN DP)

\begin{tabular}{lccc}
\hline & $\begin{array}{c}\text { S. aureus } \\
\text { (ATCC 6531P) }\end{array}$ & $\begin{array}{c}\text { S. epidermidis } \\
\text { (ATCC 1228) }\end{array}$ & $\begin{array}{c}\text { E. coli } \\
\text { (ATCC 19536) }\end{array}$ \\
\hline MIC DAN $\left(\mu \mathrm{g} \mathrm{mL}^{-1}\right)$ & 0.10 & 0.10 & 0.06 \\
MIC DAN DP 12h $\left(\mu \mathrm{g} \mathrm{mL}^{-1}\right)$ & 0.10 & 0.10 & 0.12 \\
MIC DAN DP 24h $\left(\mu \mathrm{g} \mathrm{mL}^{-1}\right)$ & 0.20 & 0.05 & 0.12 \\
MIC DAN DP 48h $\left(\mu \mathrm{g} \mathrm{mL}^{-1}\right)$ & 0.20 & 0.05 & 0.12 \\
\hline
\end{tabular}



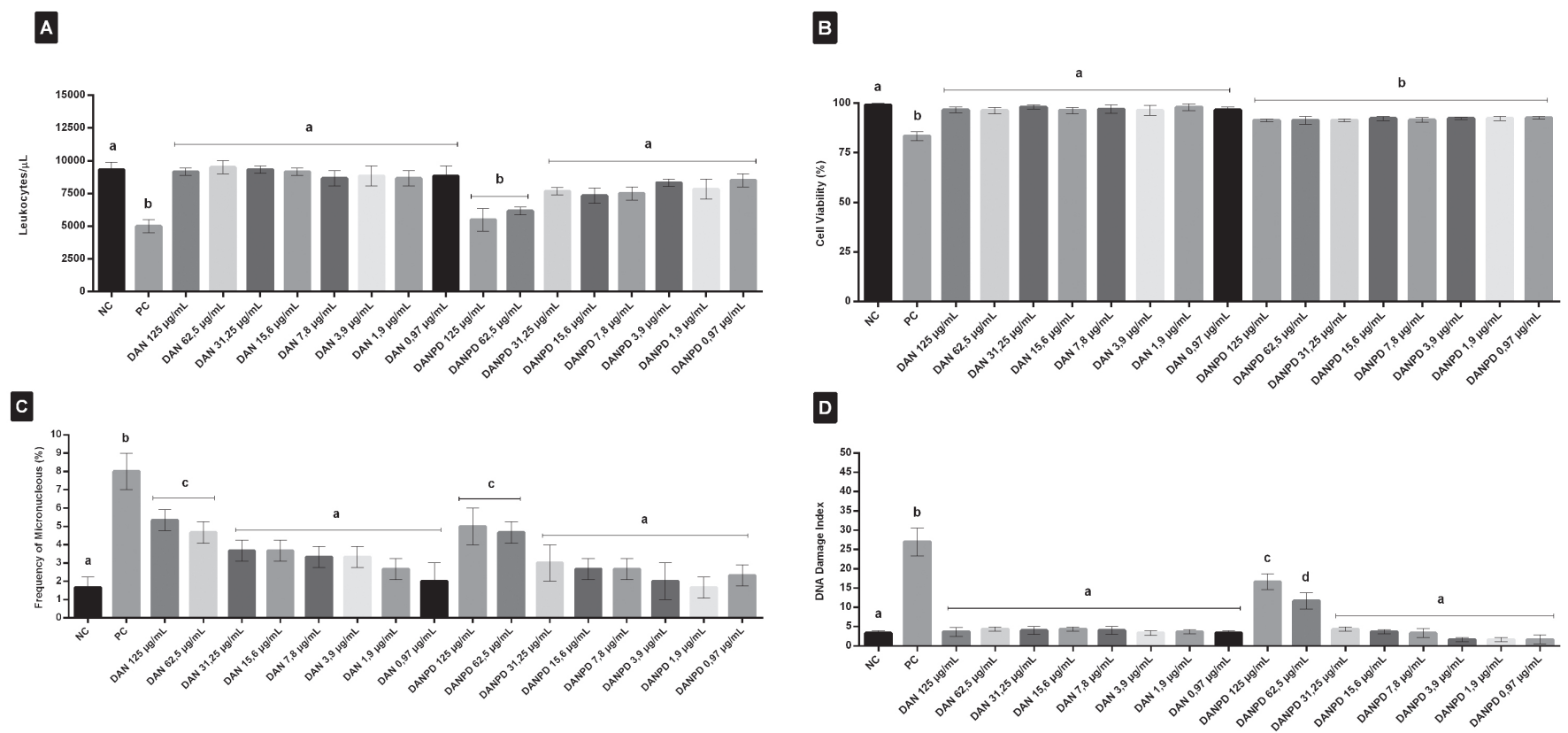

FIGURE 2 - Biological safety studies in cultures of human leukocytes: (A) Effects of DAN and DAN DP on cell proliferation; (B) Leukocyte evaluation of cell viability as measured by Trypan blue dye after exposure to different concentrations of DAN and DAN DP; (C) Comet Assay: Damage Index to DNA cells exposed to different concentrations of DAN and DAN DP; (D) Effects of DAN and DAN DP in the production of micronuclei in cell cultures.

According to many studies the toxic potential of the fluoroquinolones is directly related to the chemical structure of the molecule and varies with substituent groups. Different substituents in the basic structure of quinolones are intrinsically linked to the molecule toxicity. The genotoxic and cytotoxic potential of these drugs is mainly attributed to the presence of the cyclopropyl group, but there are also reports of toxicity of compounds which have substituent groups such as tert-butyl, 2.5 dihydrophenyl and ethyl group in position 1 (Lipsky, Barker, 1999).

Substituents at position 7 also influence the toxicity and toxic effects on the central nervous system (CNS), genotoxic and dermatological reactions. The effects on the CNS are due to interactions with GABAergic receptors, blocking the GABA union. Dermatological effects are due to the production of reactive species from interaction with ultraviolet light, causing reactions at the cellular level that manifest themselves in the form of rashes, hives, itching of the skin and other local irritations. Similarly genotoxic activity is attributed to some substituents in the same position and is more pronounced in molecules with a pyrrolidine ring compared to molecules with a substituent piperazine ring (Domagala, 1994; Briskier, Chantot, 1995).

Genotoxic potential is also related to a substituent at position 8 of the quinolones, for which fluoride, $\mathrm{C}-\mathrm{Cl}$, $\mathrm{N}, \mathrm{CH}, \mathrm{C}-\mathrm{CF}_{3}$, and $\mathrm{OR}$ are mainly responsible. In the same position photosensitivity reactions are attributed to fluoride and methoxy substituents, as described for lomefloxacin and sparfloxacin (Briskier, Chantot, 1995).

\section{Identification of the photodegradation products by LC-ESI-MS}

The results using LC-ESI-MS showed that the main degradation products under photolytic conditions have the following molecular mass: $358.1 ; 251.07$ and $291.10 \mathrm{~g} \mathrm{~mol}^{-1}$ and were named DP1, DP2 and DP3. These degradation products coincide with the degradation products DP1, DP5 and DP12 cited in the literature by Hubicka et al. (2014).

\section{In silico toxicology studies}

The theoretical risks of toxicity, such as tumorigenic, mutagenic, irritant effects, and damage to the reproductive system by DAN DP1, DAN DP2, and DAN DP3, indicated in this work, were first studied using Osiris software. Osiris is based on the analysis of a precomputed set of structural fragments that gave off toxicity alerts when they were encountered in the molecule. This program uses the drug database marketed and also Fluka chemical compounds (no therapeutic drugs) to assess the frequency of each fragment present in the compounds studied. All results for chemical structure and standard $\mathrm{H}_{2} \mathrm{O}_{2}$ using Osiris software are shown in Table III. 
TABLE III - Prediction of theoretical toxicity values of DAN DP and $\mathrm{H}_{2} \mathrm{O}_{2}$

\begin{tabular}{lcccc}
\hline Toxicity risk & DP1 & DP2 & DP3 & $\mathrm{H}_{2} \mathrm{O}_{2}$ \\
\hline Mutagenic & $(+)$ & $(+)$ & $(+)$ & $(+++)$ \\
Tumorogenic & $(+)$ & $(+)$ & $(+)$ & $(+++)$ \\
Irritant & $(+)$ & $(+)$ & $(+)$ & $(+++)$ \\
Reproductive system & $(+)$ & $(+)$ & $(+)$ & $(+)$ \\
\hline
\end{tabular}

The scale of risk of toxicity varies from low $(+)$, medium $(++)$ and high $(+++)$ calculated using the Osiris Property Explorer program.

The evaluation of these degradation products showed a prediction of a low risk of causing theoretical toxic effects, tumorigenic and mutagenic effects, and damage to the reproductive system compared with the high risk for $\mathrm{H}_{2} \mathrm{O}_{2}$. The software also suggested that there is a low risk of an irritant effect, and the same was observed for standard $\mathrm{H}_{2} \mathrm{O}_{2}$.

The ACD/Labs team web server is software used to predict the fragments that could lead to possible DP1, DP2, and DP3 toxic effects. This software suggests the occurrence of genotoxic properties and a toxicity mechanism. According to software, toxicity should be observed in two molecular regions. In the first molecular region, the presence of the aromatic amine moiety attached to the quinolone nucleus of DP2 and DP3 may undergo biotransformation and generate hydroxylamine which may be genotoxic to biological cells. The second region, the quinone moiety, was identified in three compounds evaluated. This chemical moiety is an electrophilic agent which may form adducts with guanine nucleobases and induce DNA damage after metabolic activation.

Once the results of the theoretical risk of toxicity in the AMES test Salmonella typhymirium was evaluated, a probability of 0.42 and 0.76 of DP2 and DP 3 , respectively to cause a mutagenic effect was determined. In comparison with molecules present in a program database, which cause effects against strains TA97a, TA98, TA100, TA102, TA104, TA1535, TA1537, and TA1538, there was no toxicity in most of the tested bacterial strains. In this scenario, DP2 showed a mutagenic effect on the TA98 strain when it was compared to compound bis2-hydroxy-4-amino-benzene (CAS 2373-98-0), with a similarity index of 0.21 . DP3 showed the same predicted effect on strain TA100 compared to the chemical structure of 3-amino-5-methylphenol (CAS: 95-84-1), similarity index of 0.18 .

pkCSM is a software based on graph-based signatures which are used to develop predictive models of central ADMET properties. This computational tool employs the calculated nodes distance and also the physicochemical properties of toxic compounds by machine learning-based predictors to predict the toxicity of chemical agents (Pires, Blundell, Ascher, 2015). With this software the prediction of DP1 and DP3 showed a positive effect on AMES test toxicity and hepatotoxicity. DP2 did not show a potential risk of a hepatotoxic effect. These compounds were not considered a hERG I and II inhibitor, that caused skin sensitization.

In toxicity predictions, two computer programs suggest the potential risks that DP2 and DP3 may have a genotoxic effect considering the AMES test database. These results are in agreement as observed with ex-vivo Comet assay studies performed here. All results suggest that DAN should be used carefully in the presence of degradation products.

\section{CONCLUSIONS}

The method developed and validated by LC proved selective for the quantitative determination of DAN and its degradation products obtained under stress conditions. The microbiological assay proved to be precise, accurate, robust and linear, but not selective to quantify the drug in the presence of degradation photoproducts. In the in vitro assay to evaluate the MIC, DAN PD showed reduced activity against $S$. aureus and $E$. coli, but it showed increased activity against $S$. epidermidis, which suggests that the degradation products have biological activity. Biological safety studies using a leukocyte culture demonstrated that the degradation products showed dose dependent cytotoxicity and genotoxicity.

\section{REFERENCES}

Advanced Chemistry Development Inc.; ACD/Labs. Software for analytical and chemical knowledge management, chemical nomenclature, and in-silico physchem and ADME-Tox. [cited 2017 Jan 14]. Available from: https://ilab.acdlabs.com/iLab2/.

Brasil. Ministério da Agricultura, Pecuária e Abastecimento, Secretaria de Defesa Agropecuária. Guia de Validação Analítica e Controle de Qualidade [Internet]. Brasília (DF): Ministério da Agricultura, Pecuária e Abastecimento, 2011. [citado em 2017 ago 8]. 72 p. (Biblioteca Nacional de Agricultura, Normas e Materiais Técnicos). Disponível em: http://www. agricultura.gov.br/assuntos/laboratorios/arquivos-publicacoeslaboratorio/guia-de-validacao-controle-de-qualidadeanalitica. pdf/download/file/Guia-de-validacao-controle-de-qualidadeanalitica.pdf. 
Briskier A, Chantot JF. Classification and structure-activity relations hips of fluoroquinolones. Drugs. 1995;49(Suppl 2):16-28.

Burow ME, Weldon CB, Tang Y, Navar GL, Krajewsky S, Reed SJ, Hammond TG, Clejan S. Beckman BS. Differences in susceptibility to tumor necrosis factor $\alpha$-induced apoptosis among MCF-7 breast cancer cell variants. Cancer Res. 1998;58(21):4940-4946.

Clinical and Laboratory Standards Institute, CLSI, Performance Standards for Antimicrobial Susceptibility Testing. Twentyfifth Informational Supplement. CLSI Document M100-S25, Wayne, PA:, 2015 [cited 2018 January 22]. Available from: https://www.researchgate.net/file.PostFileLoader. html id $=581 \mathrm{~d} 9 \mathrm{~d} 8 \mathrm{fcbd} 5 \mathrm{c} 2 \mathrm{f} 99 \mathrm{c} 04 \mathrm{~d} 4 \mathrm{~b} 1 \&$ assetKey $=\mathrm{AS} \%$ 3A424985668919296\%401478335887189.

Domagala JM. Structure-activity and structure-side-effect relationships for the quinolone antibacterials. J Antimicr Chem. 1994;33(4):685-706.

Ermer J, McB Miller JH. Method validation in pharmaceutical analysis, the guide to best practice. Weinheim: Wiley; 2005.

Escudero E, Cárceles CM, Fernadez-Varon E, Marin P, Benchaoui H. Pharmacokinetics of danofloxacin 18\% in lactating sheep and goats. J Vet Pharmacol Therap. 2007;30(6):1-6.

Farmacopeia Brasileira. 5 ed., Atheneu, São Paulo, Parte I, 5.2; 2010, 17-11.

Galarini R, Fiorini L, Angelucci F, Tovo GR, Cristofani E. Simultaneous determination of eleven quinolones in animal feed by liquid chromatography with fluorescence and ultraviolet absorbance detection. J Chromatogr A. 2009;1216(46):81588164.

Hewitt W. Microbiological assay for pharmaceutical analysis: a rational approach; Boca Raton: CRC Press; 2003.

Hubicka U, Zuromska-Witek B, Zmudzki P, Stanislawski M, Krzek J. Determination of danofloxacin and its photodegradation products by HPLC-DAD: Kinetic evaluation of the degradation process and identification of photoproducts by mass spectrometric. Anal Meth. 2014;6(8):2490-2498.

International Conference on Harmonization. ICH. Q1A R2. Stability testing of new drug substances and products. Geneva; 2003. [cited 2017 Ago 30]. Available from:
https://www.ich.org/fileadmin/Public_Web_Site/ICH_Products/ Guidelines/Quality/Q1A_R2/Step4/Q1A_R2_Guideline.pdf.

International Cooperation on Harmonisation of Technical Requirements for Registration of Veterinary Medicinal Products. VICH guidelines. VICH, VICH GL1. Validation of analytical procedures: definition and terminology; 1998. [cited 2017 Ago 30]. Available from: http://www.ema.europa.eu/ docs/en_GB/document_library/Scientific_guideline/2009/10/ WC500004341.pdf.

Kaur K, Saini SS, Malik AK, Singh B. Micelle enhanced and terbium sensitized spectrofluorimetric determination of danofloxacin in milk using molecularly imprinted solid phase extraction. Spectroch Acta Part A Molec Biomol Spectrosc. 2012;96:790-795.

Lipsky BA, Barker CA. Fluoroquinolone toxicity profiles: A review focusing on newer agents. Clin Infect Dis. 1999;28(2):352-364.

Liu ZY, Zhou X, Zhang H, Wan L, Sun Z. An integrated method for degradation products detection and characterization using hybrid ion trap/time-of-flight mass spectrometry and data processing techniques: Application to study of the degradation products of danofloxacin under stressed conditions. Anal Bioanal Chem. 2011;399(7):2475-2486.

Mckellar QA, Gibson IF, McCormac RZ. Pharmacokinetics and tissue disposition of danofloxacin in sheep. Biopharm Drugs Disposit. 1998;19(2):123-129.

Montagner SGF, Sagrillo M, Machado MM, Almeida RC, Mostardeiro CP, Duarte MM, et al. Toxicological effects of ultraviolet radiation on lymphocyte cells with different manganese superoxide dismutase ala16val polymorphism genotypes. Toxic In Vitro. 2010;24(5):1410-1416.

Osiris Property Explorer. Organic Chemistry Portal. [cited 2017 Jan 14]. Available from: http://www.organicchemistry. org $/$ prog/peo/.

Paim CS, Nogueira DR, Mitjans M, Lopez DR, Perez JL, Steppe $\mathrm{M}$, et al. Biological safety studies of gemifloxacin mesylate and related substances. Photochem Photobiol Sci. 2013;12(5):805812.

Picó Y, Andreu V. Fluoroquinolones in soil-risks and challenges. Anal Bioanal Chem. 2007;387(4):1287-1299. 
Pires DEV, Blundell TL, Ascher DB. pkCSM: Predicting smallmolecule pharmacokinetic and toxicity properties using graphbased signatures. J Med Chem. 2015;58(9):4066-4072.

pKCSM free web software. Predicting Small-Molecule Pharmacokinetic and Toxicity Properties Using Graph-Based Signatures. [cited 2017 Jan 14]. Available from: http://bleoberis. bioc.cam.ac.uk/pkcsm/prediction.

Rodríguez-Cáceres MI, Guiberteau-Cabanillas A, Bohoyo-Gil D, Cañas-Martínez MA. Quantification of danofloxacin and difloxacin in chicken tissues in the presence of sarafloxacin as interference. J Agric Food Chem. 2009;57(17):7627-7633.

Schmid W. The micronucleus test. Mutat Res. 1975;31(1):9-15.

Soler MAM. Study polymeric controlled release formulations of danofloxacin in sheep. [Doctoral Thesis]. Spain: University of Murcia, Faculty of Medicine; 2014.

Souza MVN, Almeida MV, Silva AD, Couri MRC. Ciprofloxacin an important fluoroquinolone to combat anthrax. J Pharm Braz. 2004;85:13-18.
The United States Pharmacopeia. USP 38 - NF 332015. Rockville, MD: The United States Pharmacopeial Convention; 2015.

Tice RR, Agurell E, Anderson D, Burlinson B, Hartmann A, Kobayashi H, et al. Single cell gel/comet assay: guidelines for in vitro and in vivo genetic toxicology testing. Environ $\mathrm{Mol}$ Mutagen. 2000;35(3):206-221.

Van Hoof N, De Wasch K, Okerman L, Reybroeck W, Poelmans $\mathrm{S}$, Noppe $\mathrm{H}$, et al. Validation of a liquid chromatography-tandem mass spectrometric method for the quantification of eight quinolones in bovine muscle, milk and aquacultured products. Anal Chim Acta. 2005;529(1-2):265-272.

Wolfson JS, Hooper DC. The fluoroquinolones: structures, mechanisms of action and resistance, and spectra of active in vitro. Antimicrob Agents Chemoth. 1985;28(4):581-586.

Received for publication on $04^{\text {th }}$ May 2018 Accepted for publication on $03^{\text {rd }}$ August 2018 